ESCENA

Revista de las artes
Publicación semestral. ISSN 2215-4906

Volumen 81 - Número 1 Julio - Diciembre 2021

\title{
Multitud y resistencia en el marco del "imperio" contemporáneo, según Antonio Negri y Michael Hardt
}

\author{
Multitude and Resistance in the Framework of \\ the Contemporary "Empire", According to Antonio Negri \\ and Michael Hardt
}

Pablo Bonilla Elizondo

DOI 10.15517/es.v81i1.47273

(c) (1) ()ㅛ Esta obra está bajo una licencia Creative Commons
BY NG ND Reconocimiento-No comercial-Sin Obra Derivada 


\title{
Multitud y resistencia en el marco del "imperio" contemporáneo, según Antonio Negri y Michael Hardt
}

\author{
Multitude and Resistance in the Framework of \\ the Contemporary "Empire", According to Antonio Negri \\ and Michael Hardt
}

Pablo Bonilla Elizondo ${ }^{1}$

Universidad de Costa Rica

San José, Costa Rica

Recibido: 10 de agosto de 2019 Aprobado: 30 de noviembre de 2019

\begin{abstract}
Resumen
El presente artículo aborda las teorías desarrolladas por Antonio Negri y Michael Hardt sobre el imperio global contemporáneo, los nuevos sujetos políticos y las formas de resistencia que en él operan. Estas últimas, se presentan de forma coherente con las transformaciones epistemológicas que ha sufrido el arte en las últimas décadas, las cuales han redefinido sus prácticas y sus formas de vinculación con lo político. Se concluye que la imbricación entre arte y activismo político -a diferencia de los acoples modernistas entre arte y política- permite vislumbrar el potencial y la relevancia del arte contemporáneo para la continua construcción y defensa de una sociedad democrática, solidaria y equitativa en el panorama actual.
\end{abstract}

Palabras claves: Filosofía Política; Artes Visuales; movimientos sociales; capitalismo; democracia.

1 Profesor en la Escuela de Artes Plásticas de la Universidad de Costa Rica. Doctor en Arte: Producción e Investigación por la Universidad Politécnica de Valencia, España. Código ORCID: 00000003-1906-4314. Correo electrónico: pablo.bonillaelizondo@ucr.ac.cr 
Multitud y resistencia en el marco del "imperio" contemporáneo,

Artículo según Antonio Negri y Michael Hardt

\begin{abstract}
This paper addresses the theories developed by Antonio Negri y Michael Hardt about the contemporary Global Empire, the new political subjects and the forms of resistance that operate in it. These forms of resistance are presented consistent with the epistemological transformations that has undergone art in recent decades, which have redefined their practices and their links with politics. It is concluded that the interweaving between art and political activism - unlike modernist couplings - allows us to glimpse the potential and relevance of contemporary art for the continuous construction and defense of a democratic, solidary and equitable society in the current panorama.
\end{abstract}

Key words: Political Philosophy; Visual Arts; social movements; capitalism; democracy. 


\section{Introducción}

Desde hace cinco o seis décadas, pareciera evidente una articulación entre arte y política sustancialmente distinta a la vista en la segunda mitad del siglo XIX y la primera mitad del XX, en tanto se evidenciaba con más claridad la implicación o resistencias de los artistas y sus obras en la organización e implementación de los Estados modernos. Para algunos, principalmente para aquellos anclados en cierta gramática moderna (artistas, en algunos casos), las formas y manifestaciones que se han denominado biopolíticas -en correspondencia con lo planteado por Michel Foucault (2009) en torno al control de lo corporal y la construcción de subjetividades- no solo han significado una desintegración de los colectivos representados por sus organizaciones hegemónicas (la clase obrera y sus derivados: partidos, sindicatos, patronales), sino que con ellas se ha desvirtuado todo tipo de posibilidad transformadora, militancia o incluso resistencia, en función de una inmediatez de múltiples intereses de orden individual: hedonistas o narcisistas.

Evidentemente, ese tipo de afirmación encuentra uno de sus orígenes en cierta ilusión retrospectiva producto de un reduccionismo didáctico. La periodización es una de las estrategias más usuales para estas reducciones, sobrecargada de un contenido ideológico que estrecha la lente sobre el pasado para construir una noción de progreso a partir de consecuencias nítidas producto de causas fechables y "enseñables". Por supuesto, fuera de foco siempre quedan prácticas y manifestaciones alternas y fugitivas que, por su propia naturaleza, comprometen estos grandes relatos.

Desde la periodización didáctica -y la ilusión retrospectiva propia de la noción de progreso que esta fomenta- no es casual que, con premura, se contemple la práctica artística contemporánea en su vínculo con lo político como parte de un tipo de amor fati, retiro, indiferencia, conformismo, apatía, pérdida del camino o agotamiento estilístico -manierismo en suma- posterior a un momento heroico, en el cual el decaer de cierta gloria de la organización política se transfiere a lo estético para hacer perder su autonomía. Un claro ejemplo de este tipo de periodización didáctica se presenta en la publicación Art and social change (Bradley \& Esche, 2007): un compendio de textos diversos que, como indica su editor Will Bradley, evidencian un conjunto de "momentos en los cuales el deseo por un cambio social ha llevado a artistas de la esfera del arte moderno a alinearse con movimientos sociales más amplios, o a romper con la institución artística" (Bradley \& Esche, 2007, p. 9). Este documento ordena sus textos -entre los cuales figuran cartas de Gustave Courbet hasta glosarios de guerrilla mediática de la década de 1990-alrededor de cuatro momentos de 
Multitud y resistencia en el marco del "imperio" contemporáneo,

Artículo según Antonio Negri y Michael Hardt

conflicto político: el levantamiento de la Comuna de París en 1871, la Revolución Rusa en 1917, Mayo del 1968 y, por último, el final de la Guerra Fría en 1989.

Como claramente sugieren los mismos Bradley y Esche (2007), estas fechas no se pueden considerar como marcas definitivas, sino como referencias de una historicidad relativa que pretende organizar un conjunto de textos diversos (en realidad las fechas podrían ser fácilmente sustituidas por otras sin obligar un cambio en el contenido del documento ni su orden). Sin embargo, la periodización evidencia en sí misma el orden didáctico usual que aborda las relaciones entre arte y política bajo un flujo de causas y consecuencias, en este caso dentro de la historia y progresión del marxismo y cierta dependencia artística representativa de sus transformaciones históricas.

Ahora bien, no se trata de negar la historia, sino evitar el malentendido recurrente que ya denunciaba Foucault en algún conversatorio: "no hay que confundir historia de la filosofía y arqueología del pensamiento" (Foucault, 1995, p. 54). Se suscribe aquí esa diferencia sustancial al respecto de la historia política y el pensamiento artístico para problematizar una divergencia ubicable y constatable entre saberes que no se suceden ni se heredan, sino que se enfrentan quizás en un mismo territorio. En ese sentido, se pretende en este escrito someter a un proceso de análisis crítico una muestra de acontecimientos que articulan arte y política en el ámbito del pensamiento contemporáneo que, en contra de cierta hegemonía, intenta subrayar la potencia de los matices, imbricaciones, excepciones, cortes, divergencias y tangencialidades que, desde la perspectiva moderna, no serían más que residuos afuera de la historia y el progreso de Occidente.

Para ello, se abordarán las teorías desarrolladas por Antonio Negri y Michael Hardt en su texto Multitud: Guerra y democracia en la era del Imperio (2004), del cual se desprenden los conceptos de "multitud", "biopoder" y "producción biopolítica". Estos conceptos posibilitan comprender cierto fenómeno contracultural que, desde la década de 1970, se abría paso ajeno a los sujetos políticos modernos -el pueblo, la masa o el proletariado-, desde los cuales se prejuzgaba, por una parte, a las nuevas formas de hacer política como improductivas o individualistas y, por otra parte, a la producción contemporánea como pura banalidad o expresión narcisista.

Casualmente, ese descrédito a la acción colectiva bajo una supuesta indiferencia propia del hedonismo del capitalismo tardío también colmó de preocupaciones a los intelectuales de izquierda sobre los destinos y los parajes que Michel Foucault empezó a visitar en

ESCENA. Revista de las artes, 2021, Vol. 81, Núm. 1 (julio-diciembre), pp.18-43 
sus últimos seminarios y publicaciones. El hecho de que el conjunto de investigaciones que inauguró con el Nacimiento de la biopolítica (Foucault, 2009) estuviera claramente anclado al liberalismo económico elevó ciertas sospechas que, a mi entender, Foucault prontamente despejó al acudir al terreno lejano del pensamiento helenístico y romano. Sin embargo, para muchos entusiastas de la democracia heroica del periodo clásico griego y las alturas del idealismo platónico, acudir a ese terreno probablemente alimentó las ideas de una posmodernidad cínica, apática de toda militancia y decadente en fin, en tanto las formas de oposición ante el liberalismo individualista se asemejaban, a simple vista, a aquello a lo que hacían frente. No obstante, en contra de estos supuestos llenos de ilusión retrospectiva, es claro que Foucault encontró en el mundo helenístico un conjunto de técnicas o prácticas de sí (technē tou biou) que no se detenían en lo individual, sino que, por el contrario, eran tendientes a la colectivización en la definición de una filosofía práctica y política, la cual consideró susceptible de ser confrontada con la manifestación de fenómenos culturales resonantes del final del siglo XX (tiempo en el que el autor vivió y del que algunos postulan que huía).

Con relación a lo anterior, parece sumamente inocente creer que Foucault no visualizó en la crisis de la democracia griega un contrarelato de la crisis democrática de la segunda mitad del siglo XX, cuestión que experimentó durante sus desplazamientos entre las colonias francesas y París. Por lo tanto, es fundamental abordar los desarrollos realizados por Negri y Hardt, quienes parten de Foucault para ahondar en la organización imperial que opera con su hegemonía sobre las democracias contemporáneas. Dicha cuestión tiene el propósito de eliminar las preocupaciones remanentes de una izquierda de esencia modernista que aún plantea un descrédito machista hacia lo personal como político y de la potencia de los cuerpos: su elementalidad carnal y de una producción que excede lo material. Ese mismo potencial múltiple de los cuerpos es lo que aquí se postulará como producción artística, ajena a las nociones modernistas del objeto artístico y su autoría.

\section{El imperio y la multitud}

Para Hardt y Negri (2004), el nuevo imperio en la era de la globalización, distinto al imperialismo que practicaron las potencias modernas en la extensión de los estados colonialistas sobre territorios ajenos, emerge hoy como un poder en red: una nueva forma de soberanía global que ejerce su control no desde un solo punto centralizado y dominante, sino que organiza y reparte sus fuerzas en múltiples jerarquías variables con dominios nodales relativos: 
Multitud y resistencia en el marco del "imperio" contemporáneo,

Artículo según Antonio Negri y Michael Hardt

Lo que emerge hoy, en cambio, es un "poder en red", una nueva forma de soberanía, que incluye como elementos principales o nodos a los estados-nación, junto con las instituciones supranacionales, las principales corporaciones capitalistas y otros poderes. En la red del Imperio no todos los poderes son iguales, por supuesto. Muy al contrario, algunos estados-nación tienen un poder enorme, y otros casi ninguno, y lo mismo ocurre con las demás corporaciones e instituciones que componen la red (Hardt \& Negri, 2004, p. 14).

Ahora bien, para ambos autores, los nodos supranacionales y las grandes corporaciones capitalistas tienen un poder mayor que los estados-nación, sobre todo por la capacidad de actuar de forma autónoma al mismo tiempo que ejercen una influencia política sobre estos, incluso coercitiva ante los más pequeños. Esta cuestión se ha constatado en la última década, al aminorarse notablemente el alcance de la democracia y la voluntad popular para determinar el ejercicio operativo de la mayoría de los estados, los cuales privilegian las relaciones de conveniencia entre la clase política y los lobbies corporativos. La principal herramienta para minar la democracia y la participación popular en ella es el uso estratégico de una nueva forma de guerra continua, enfáticamente implementada por el miedo y el shock ${ }^{2}$ que la mayoría de las veces no han encontrado fundamento más allá que el propio enunciado que emite el lider político de turno ${ }^{3}$ armonizado con los intereses de las grandes coorporaciones y las organizaciones supranacionales.

Ese estado de guerra continua exteriorizada produce hoy la perpetuación paradójica de regímenes excepcionales que suprimen los derechos democráticos bajo la seguridad preventiva en los estados de emergencia. Como si no fuera suficiente, esta nueva forma de guerra evade la legislación mundial que la regula para refundar un nuevo tipo de legalidad a partir de ella; además, suplanta las formas previas propias de la modernidad. Como afirman Negri y Hardt (2004), el rol de la guerra en esta nueva forma de imperialismo ya no es la continuación de la política, como afirmaba el adagio de Clausewitz ${ }^{4}$, ni tampoco está

2 Doctrina del Shock (Kleim, 2007).

${ }^{3}$ Claro ejemplo es la invasión a Irak promovida por Bush, Aznar y Blair sin pruebas reales de armas de destrucción masiva por parte del gobierno irakí o haber estado vinculado por los ataques terroristas del 11 de setiembre de 2001.

${ }^{4}$ El postulado de Clausewitz es el siguiente: "la Guerra es la continuación de la política por otros medios" (citado en Negri \& Hardt, 2004, p. 26)

ESCENA. Revista de las artes, 2021, Vol. 81, Núm. 1 (julio-diciembre), pp.18-43 
subordinada al derecho internacional que previo a ella la declaraba y la instrumentalizaba bajo cierta legalidad, sino que ahora la guerra es el fundamento de la política, la construye y la deriva de su propia legalidad bélica.

Lo específico de nuestra época, como hemos dicho, es el hecho de que la guerra, que antes era el último elemento de la secuencia de poder -la fuerza letal como último recurso-, pasa a ser el primero y primordial, el fundamento de la política misma. La soberanía imperial crea el orden, no poniendo fin a "la guerra de todos contra todos", como diría Hobbes, sino proponiendo un régimen de administración disciplinaria y control político directamente basado en la acción bélica continuada. En otras palabras, la aplicación constante y coordinada de la violencia se convierte en condición necesaria para el funcionamiento de la disciplina y el control. Para que la guerra asuma este papel social y político fundamental es necesario que cumpla una función constituyente o reguladora; debe constituir una actividad de procedimiento y al mismo tiempo una actividad ordenadora y reguladora que cree y mantenga las jerarquías sociales, una forma de biopoder encaminada a la promoción y regulación de la vida social (Hardt \& Negri, 2004, pp. 43-44).

Siguiendo a los autores, por la necesidad de su perpetuación, la guerra es la principal herramienta para ejercer el biopoder, en tanto instrumento militar-policial de seguridad ${ }^{5}$ y ya no de defensa aplicado a lo interno sobre aquellos que debe proteger bajo un supuesto valor preventivo. Es decir, el dispositivo no se aplica sobre el enemigo, sino sobre los propios ciudadanos que protege. Como afirman Hardt y Negri: "además de acarrear la muerte, la guerra global también ha de producir la vida y regularla" (Hardt \& Negri, 2004, p. 42). De esa forma, el biopoder se ejerce desde la guerra por la posibilidad misma de la destrucción (en la segunda mitad del siglo XX bajo la amenaza del armamentismo nuclear, hoy bajo el terrorismo), pero, además, se ejerce diariamente y se expande a la vida cotidiana, dado que debe regular y asegurar en positivo la vida por medio de los dispositivos de seguridad que previenen de la delincuencia común y el narcotráfico (no es casualidad que en México se haya declarado un Guerra a las Drogas). Así, la guerra no representa únicamente la posibilidad de la extinción, sino que también se adjudica la continuidad de la vida y, por eso, debe ser aplicada en su cotidianidad y ya no de forma eventual.

5 Esto es evidente en la "guerra contra el terrorismo". Desde setiembre del 2001, claramente se concreta esta transformación (Hardt \& Negri, 2004, p. 42). 
Multitud y resistencia en el marco del "imperio" contemporáneo,

Artículo según Antonio Negri y Michael Hardt

En estos estados de excepción democrática, se configuran a su vez otras formas de resistencia que de igual manera deben operar fuera de las organizaciones centralizadas y la democracia representativa, las cuales construyen sus propias conexiones internacionales. Surgen así las luchas en red, claramente preocupadas por enfrentar las formas de biopoder con estrategias que, consecuentemente, no podrían llevar otro nombre más que biopolíticas. La biopolítica, como afirman Negri y Hardt, es inherente a la sociedad y sobrepasa la naturaleza materialista del intercambio económico: es una fuerza productora de bienes inmateriales, ideas, saberes, conocimiento, relaciones, comunicación, sentidos y significaciones, que imbrican lo social, lo cultural y lo vital con lo político. Ahora bien, la biopolítica se distingue del biopoder en tanto que, precisamente, lo enfrenta como ente "situado por encima de la sociedad, trascendente, a título de autoridad soberana que impone su orden" (Hardt \& Negri, 2004, p. 123). La biopolítica en cambio surge y se enriquece de procesos colaborativos conformados por agentes diversos en estructuras horizontales, dando contenido y reconfigurando a la democracia misma.

El hecho de que las formas biopolíticas de resistencia no tengan el amparo en los cuerpos sociales tradiciones -como el proletariado o el pueblo- ni se proyecten en ellos para la construcción de una alternativa, como algunos proyectos restauracionistas de izquierdas y derechas defienden ${ }^{6}$, no implica otra cosa más que el hecho de que estas formas biopolíticas deben ser redefinidas dentro de su propia posibilidad "como una red abierta y expansiva, donde todas las diferencias pueden expresarse de un modo libre y equitativa, una red que proporciona los medios de encuentro que nos permitan trabajar y vivir en común" (Hardt \& Negri, 2004, pp. 15-16). Por tanto, ante esta nueva forma imperial en el contexto de la globalización, emerge su proyecto por redefinir los alcances de la multitud, entendida esta como un nuevo sujeto político construido por una heterogeneidad de subjetividades,

6 Ambos autores lo plantean de esta manera: "la sociedad posmoderna se caracteriza por la dislución de los cuerpos sociales tradicionales. Los dos bandos del debate entre 'modernistas' y 'posmodernistas', que hasta no hace mucho animó las polémicas académicas y culturales, reconocen esa disolución. Pero el verdadero motivo que los separa es que los modernistas quieren proteger o resucitar los cuerpos sociales tradicionales, mientras que los posmodernistas aceptan o incluso celebran su disolución. Por ejemplo, en Estados Unidos muchos autores evocan con nostalgia las formaciones sociales del pasado ante el fracaso de las organizaciones sociales tradicionales y la amenaza de una sociedad fragmentada e individualista. Estos proyectos restauracionistas -que se sustentan generalmente en la familia, la Iglesia y la patria- solían formar parte de la visión ofrecida por la derecha, pero últimamente los panegíricos más interesantes y apasionados provienen de la corriente mayoritaria de la izquierda" (Hardt \& Negri, 2004, pág. 225).

ESCENA. Revista de las artes, 2021, Vol. 81, Núm. 1 (julio-diciembre), pp.18-43 
singularidades y cuerpos diversos que se encuentran bajo diferentes núcleos relativos, para conformar un tipo de resistencia articulada en forma nodal o en red: una alternativa viva que crece en el interior del imperio. Así lo plantean Hardt y Negri:

Por una parte el Imperio extiende globalmente la red de jerarquías y divisiones que mantienen el orden mediante nuevos mecanismos de control y de conflicto constante. Pero, sin embargo, la globalización también crea nuevos circuitos de cooperación y colaboración que se extienden por encima de las naciones y de los continentes, y que hacen posible un número ilimitado de encuentros. Esta otra faceta de la globalización no significa que todos vayamos a ser iguales en el mundo, pero brinda la posibilidad de que, sin dejar de ser diferentes, descubramos lo común que nos permite comunicarnos y actuar juntos (Hardt \& Negri, 2004, p. 15).

Así, a pesar de que las formas de oposición política ante esta nueva forma imperial comparten un terreno infraestructural común, esto no implica inherentemente una condena del acto de resistir por su confluencia o asimilación. Por el contrario, el hecho de que la multitud ejerza su accionar sobre la misma infraestructura, en vez de esconder los mecanismos de difusión y las estrategias retóricas que organizan las ideologías hegemónicas, los evidencia, la mayoría de las veces por medio de cierta performance paródica y crítica que tiende a expandirse en ese descubrimiento de lo común. Esto debido a que esa red, además de expansiva, debe constantemente afirmarse a sí misma: la multitud se acredita en la diferencia intersubjetiva que se asevera en la diversidad de los cuerpos, ya que solo a través de ellos -a través de la elementalidad de la carne- es posible reorientar el ruido de las baterías mediáticas del imperio, cuyo instrumento de dominación, como proponen los autores citados, es la guerra perpetua que asfixia y precariza la vida social.

Ahora bien, en este nuevo tipo de resistencias en red organizadas desde lo biopolítico, convergen un cúmulo de intereses variados, corporales en su mayoría, aunque de-localizados y de diferente naturaleza. Por tanto, es importante distinguir las luchas biopolíticas de la lucha de clases y, con ello, desjerarquizar las reivindicaciones de género, raciales, ecológicas, entre otras a esta noción claramente moderna que persiste en afirmarse prioritaria desde cierto conservadurismo de izquierdas. Como afirman Hardt y Negri (2004), la lucha de clases era consistente y se centraba en sus propios intereses y deseos, soportando y reafirmando esa uniformidad ante una figura monolítica y hegemónica representada por el Estado y su connivencia con las clases poderosas. Las nuevas formas de resistencia son siempre producción en minoría, en el sentido de que carecen de numeración, incluso el 99\% 
Multitud y resistencia en el marco del "imperio" contemporáneo,

Artículo según Antonio Negri y Michael Hardt

que se enfrenta al 1\% en las proclamas de Occupy Wall Street solo juega retóricamente con ese supuesto mayoritario. Como afirman Deleuze y Guattari, a las minorías no les conviene las formas del Estado ni los axiomas del capital, sino que los atraviesan: "no se efectúan en los conjuntos numerables que le sirven de modelos sin constituir a la vez conjuntos no numerables que atraviesan y trastocan esos modelos" (Deleuze \& Guattari, 2000, pp. 475476). En ese sentido, carecen de uniformidad numeral, por ello mismo, Hardt y Negri las han definido como "luchas de la multitud", una noción que afirma esta condición innumerable en perpetua minoría, diferente a otros sujetos sociales previos como el pueblo, las masas o la clase obrera que acreditaban sus luchas y esperanza de triunfar en ser o constituirse en una mayoría uniforme.

El vocablo pueblo reduce la diversidad de una población a una identidad única. El pueblo es uno, sintetiza y reduce a un mismo ente todas las diferencias sociales (etarias, de género, raciales, étnicas u otras) de los individuos que constituyen un territorio, sea este pequeño como una isla del Caribe o todo el globo terráqueo. "Las partes componentes del pueblo son indiferentes dentro de su unidad; se convierten en identidad negando o dejando de lado las diferencias" (Hardt \& Negri, 2004, p. 127). La multitud en cambio es plural, contrasta con el pueblo en tanto su unidad no es indiferenciada ni reduce a la uniformidad a sus individuos, sino que está conformada por un conjunto de singularidades, entendiendo "por singularidad un sujeto social cuya diferencia no puede reducirse a uniformidad: una diferencia que sigue siendo diferente" (Hardt \& Negri, 2004, p. 127). De ese modo, cada singularidad para conformar la multitud debe mantener diferencia como necesaria para su articulación con otros cuerpos distintos:

La multitud se compone de innumerables diferencias internas que nuncapodrán reducirse a una unidad, ni a una identidad única. Hay diferencias de cultura, de raza, de etnicidad, degénero, de sexualidad, diferentes formas detrabajar, de vivir, de ver el mundo, y diferentes deseos. La multitud es una multiplicidad de tales diferencias singulares (Hardt \& Negri, 2004, p. 16).

Al contrario del pueblo, la multitud se organiza en red y se manifiesta de forma más o menos espontánea, no está unificada, ni localizada o delimitada territorialmente, sino que existe esparcida y se rige por los acontecimientos singulares. Por ello, es fundamental distinguir a la multitud de las masas o las turbas porque, si bien es cierto que estos conceptos designan colectivos plurales que también se rigen por apariciones eventuales, es claro que no actúan por sí mismos, son conducidos por diferentes influjos que los llevan 
a actuar fuera del reconocimiento de cualquier singularidad en sus filas. La multitud, en cambio, es "un sujeto social activo, que actúa partiendo de lo común, de lo compartido por las singularidades" (Hardt \& Negri, 2004, p. 128). Es cierto que a las masas, las turbas o la gente tampoco se les pueden reducir a una unidad estable, pero de cierta forma duermen esperando un acontecimiento específico, extremo y traumático, pues están siempre supeditados a cierto tipo de guerra.

Asimismo, es fundamental distinguir a la multitud de la clase obrera. Como indican Hardt y Negri, la clase obrera se ha utilizado frecuentemente como un concepto excluyente que diferencia a trabajadores de los patrones, pero también a los obreros fabriles de otras fuerzas laborales en sectores de servicios o incluso agrícolas. Esto tenía cierto sentido en el contexto de la revolución industrial, en el cual se puede decir que el peso de la economía recaía sobre esa fuerza laboral. Pero es claro, como demuestran los autores en su amplia exposición ${ }^{7}$, que estas condiciones de dominio han disminuido en la actualidad en favor de otros sectores como el sector de servicios.

Sin embargo, la diferencia más relevante de la clase obrera con la noción de multitud yace en que limita su foco de atención exclusivamente a la producción económica y, por tanto, no solo excluye la población de trabajo no remunerado (doméstico en su mayoría), sino también a otras poblaciones que son productoras de bienes inmateriales, culturales y sociales: estudiantes, artistas, pacientes psiquiátricos, población carcelaria, desempleados, niñez, personas sin techo, pobres, y a los mismos trabajadores fuera de su horario laboral, quienes -además de los objetos materiales que producen en su tiempo de trabajo- producen inmaterialidades: ocio, afectos, relaciones sociales y familiares, organización política, entre otros. Todos estos grupos son productores de lo social, producen conocimiento, ideas, afectos, relaciones sociales, políticas y éticas. Por lo tanto, en suma, desde esa perspectiva, la clase obrera es excluyente de una serie de poblaciones y niega una producción que no es meramente económica.

El conflicto primordial de esta visión de la clase obrera -y lo que claramente la ata a los tiempos de la modernidad- es la atribución usual como clase de base para una construcción de lo social excluyente, que supone a la cultura, el arte, la comunicación y la vida cotidiana, en suma, derivadas exclusivamente de una matriz económica por distribuir. Opuesto a los tiempos de la clase obrera, la producción hoy es un hecho social que contiene un registro

7 Principalmente, en el Prefacio de Multitud. Guerra y democracia en la era del Imperio (Hardt \& Negri, 2004, p. 13-20) 
Multitud y resistencia en el marco del "imperio" contemporáneo,

Artículo según Antonio Negri y Michael Hardt

material y económico consustancialmente importante, pero que no se le jerarquiza exclusivamente bajo una organización centralista, sino que se le articula en red con otras formas de producción que no se limita a lo material, sino que suma ideas, diseño, sentires, posturas éticas u otras. Negri y Hardt (2004) han denominado este fenómeno como "producción biopolítica", concepto bajo el cual es posible plantear formas alternas de organización y resistencia ante el biopoder basadas en el intercambio corporal, de los afectos, de la diversidad y de la producción inmaterial que de ella surge. Allí, como concluyen los autores, yace la posibilidad misma de la democracia:

En la medida en que la multitud no es una identidad (como el pueblo) ni es uniforme (como las masas), las diferencias internas de la multitud deben descubrir "lo común" que les permite comunicarse y actuar mancomunadamente. En realidad, lo común que compartimos no se descubre, sino que se produce. ... Nuestra comunicación, colaboración y cooperación no se basan únicamente en lo común, sino que lo producen, a su vez, en una relación espiral siempre en aumento (Hardt \& Negri, 2004, pp. 17-18).

La producción biopolítica, al ser la construcción de lo común en esa articulación de cuerpos singulares que crean conceptos, afectos, relaciones y sus propias luchas políticas, deviene en la potencia misma del concepto de la multitud, es aquello que la posibilita y la agencia. Por tanto, la producción biopolítica no se detiene ni se organiza de forma descendente a partir de fenómenos económicos, sino que abarca a la vida misma y posibilita formas alternativas de organización: es un arte de vivir que se teje y resiste a partir de las relaciones humanas y sus afectos.

Por su parte, la singularidad de los cuerpos es la que reformula el proyecto político de la lucha de clases, ya que no se eleva sobre la base de ninguna uniformidad, sino sobre las condiciones diferenciadas y singulares de la diversidad, una diversidad que en su articulación produce lo común. De esa forma, las diferencias se convierten en potencia que posibilita la conexión entre cuerpos antes inconexos:

Una vez que hemos reconocido la singularidad, lo común empieza a emerger. En realidad, las singularidades se comunican, y pueden hacerlo gracias a lo común que comparten. Entre otras cosas tenemos un cuerpo con dos ojos, diez dedos en las manos y otros tantos en los pies. Compartimos la vida en este planeta, compartimos regímenes capitalistas de producción y explotación, y compartimos sueños comunes acerca de un futuro mejor. Por consiguiente, nuestra comunicación, colaboración y

ESCENA. Revista de las artes, 2021, Vol. 81, Núm. 1 (julio-diciembre), pp.18-43 
cooperación no se basan solo en lo común existente, también producen a su vez nuevos elementos comunes. Todos hacemos y rehacemos todos los días lo común que compartimos [el destado aparece así en el original] (Hardt \& Negri, 2004, pp. 159-160).

En síntesis, la multitud representa una respuesta que convive con el biopoder en un marco estructural nodal, pero que, dado que se conforma en la diversidad de la carne, proyecta un conjunto de riquezas propias que le permiten su propia subversión a partir de cierta polifonía carnavalesca. Esta condición doble, en tanto concepto operativo que comparte una infraestructura con aquello a lo que se resiste, como Negri y Hardt (2004) indican, hace que sea fundamental trasponer el concepto a las prácticas que lo expresan. Así, será elemental trasponer el concepto de multitud al terreno de las manifestaciones artísticas para problematizar su articulación y la potencia que de ella deviene, cuestión determinada por esa misma polifonía carnavalesca.

\section{Artivismo: la carne, lo monstruoso y el carnaval}

La carne es lo primero y lo más elemental, es lo que une y al mismo tiempo diferencia, lo que permite la articulación monstruosa de los cuerpos distintos y diversos. El monstruo es en esencia aquello con lo cual se comparte lo elemental, pero que se niega, ya que señala las diferencias que atacan directamente los cánones, los supuestos sociales y los hábitos que precisamente cubren la carne para ocultarla en su naturaleza desreglamentada. El monstruo también implica la reivindicación del placer corporal en todos sus múltiples anclajes maquínicos, más allá de los supuestos genitales, reproductivos, convencionales y morales. Un monstruo no se pregunta por lo que el cuerpo es, lo que no debe hacer y cómo debe reglamentarse, sino por lo que el cuerpo puede hacer ${ }^{8}$.

Desde ese principio, el monstruo asume su cuerpo como potencia y no como régimen, lo cual redime la imposición moral que se le ha impuesto peyorativamente como objeto de terror impúdico. Esa redención es fundamental para las Guerrilla Girls, por ejemplo, quienes reivindican su elementalidad gracias a un nuevo ente mitológico: cuerpo de mujer, cabeza de gorila. Esa condición elemental, exenta de cualquier supuesto, predisposición o rodeo dogmático, Hardt y Negri (2004) la toman de Maurice Merleau-Ponty9 para profundi-

8 Esta serie de preguntas las plantea Judith Butler siguiendo a Deleuze en el documental Examined Life (Taylor, 2008).

9 Por ejemplo de la siguiente cita: "la carne no es materia, no es mente, no es sustancia. Para designarla tendríamos que utilizar la antigua noción de 'elemento', en el sentido en que se solía nombrar 
Multitud y resistencia en el marco del "imperio" contemporáneo,

Artículo según Antonio Negri y Michael Hardt

zar en su carácter potencial: la carne de la multitud es un poder vital informe que no deja de expandirse produciendo exceso, signos sobre signos. "Desde la perspectiva del orden y el control políticos, entonces, la carne elemental de la multitud es terriblemente evasiva ya que nunca puede ser completamente atrapada en la jerarquía orgánica de un cuerpo político" (Hardt \& Negri, 2004, pp. 227-228). La carne no tiene recubrimiento, es la desnudez misma, lo cual la convierta en una fuerza incontrolable que evidencia de forma crítica lo que ha sido tapado.

Imagen 1. Fotografía Guerrilla Girls en el V\&A Museum, Londres

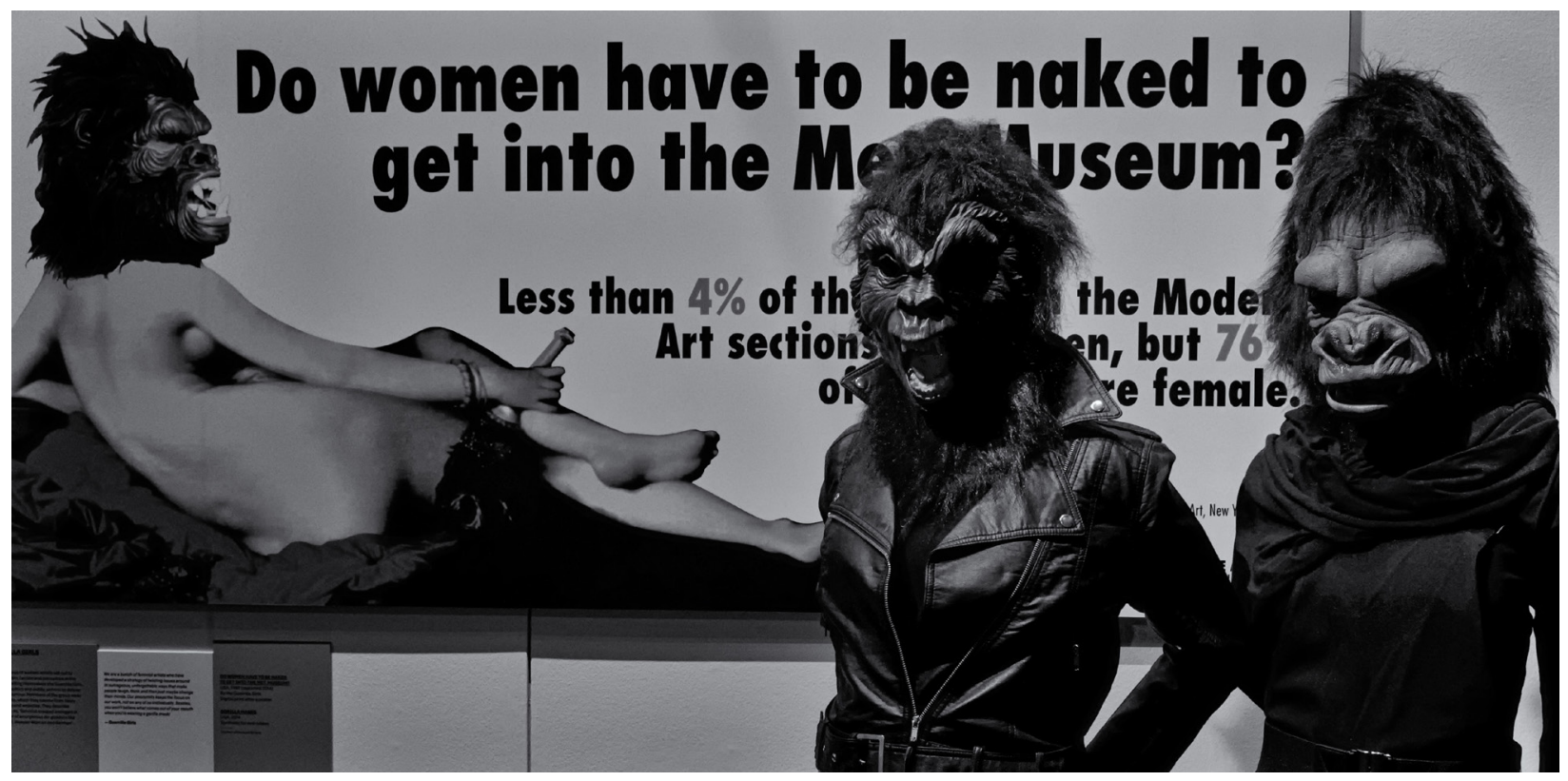

Fuente: Huybrecht, E. (2014).

Ahora bien, no es para nada casual, como hacen notar Hardt y Negri, que estos fenómenos de la multitud aparezcan de manera similar y se fundamenten en el pensamiento feminista y en las luchas identitarias que tras ella se suman sin perder su singularidad. El feminismo es el gran ataque a la organización patriarcal no solo porque representa la lucha directa por la equidad de las mujeres, sino también porque cada vez más se consolida como un conjunto nodos fundamentales para la potencia de la multitud, no solo por atribución histórica, sino porque en cierta medida la ha hecho posible como territorio de batalla, como lo remarca la poderosa imagen de Barbara Kruger, Your body is a battleground (1989).

el agua, el aire, la tierra y el fuego" (Merleau-Ponty, citado en Hardt \& Negri, 2004, p. 227). 
El biopoder del capitalismo global pretende convertir la multitud en una masa adherida a un consumo. Los Estados, por su parte, también desean que la multitud se uniforme en el pueblo bajo nacionalismos y patriotismos. En ambos escenarios el cuerpo de la mujer es reducido: en el primero, se convierte en objeto de consumo sexual; en el segundo, resguarda el hogar detrás de las marchas masculinizadas de las fuerzas militares, cuestión que, por su parte, retrató con mucha pertinencia Martha Rosler en la serie de fotomontajes House beautiful: Bringing the War Home (1969-1972, 2004-2008).

Además, como señalan Negri y Hardt (2004), en ese mismo escenario la multitud emerge en respuesta a la represión de la carne y lo corporal que, históricamente, la moral cristiana y su secularización en el capitalismo ha ejercido sobre el cuerpo de la mujer. De igual forma, el feminismo sabe que el cuerpo de mujer es el campo de batalla y el instrumento para ganarla y reclamar el territorio; de manera que el cuerpo deviene máquina-nómada y corporal, principio diferenciado y monstruoso de la carne que debe actuar sobre un terreno en disputa. En suma, los monstruos, la variedad de todos ellos como dicen Negri y Har$\mathrm{dt}$, son peligrosos para las jerarquías políticas porque "atestiguan que todos somos singulares, y que nuestras difeImagen 2. Untitled (your body is a battleground)

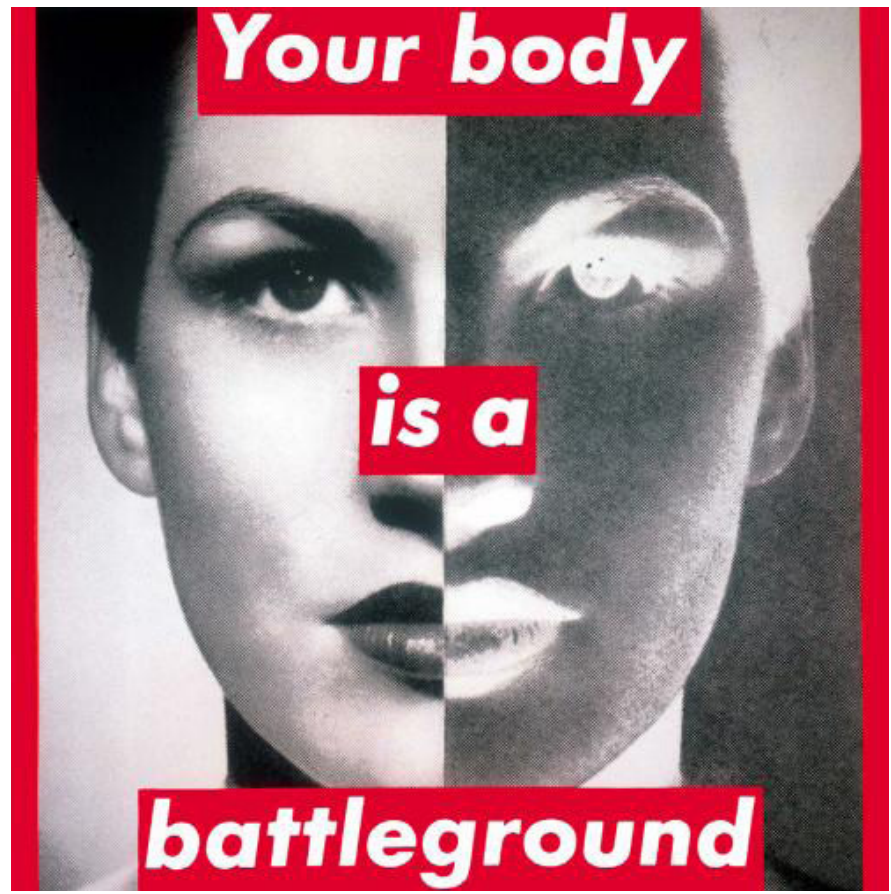

Fuente: Kruger, B. (1989). rencias no pueden reducirse a un cuerpo social unitario" (Hardt \& Negri, 2004, p. 229). En tal sentido, a la monstruosidad del cuerpo de la mujer se le debe sumar la monstruosidad del homosexual, del transexual, del indígena, del negro o, incluso, el chancletudo, el perroflauta, chairo ${ }^{10} \mathrm{o}$ el intelectual de izquierdas.

${ }^{10}$ Aunque sus usos pueden variar, estos descalificativos de uso local en Costa Rica, España y México de forma correspondiente, se refieren a los jóvenes universitarios implicados de una forma $u$ 
Multitud y resistencia en el marco del "imperio" contemporáneo,

Artículo según Antonio Negri y Michael Hardt

De esa manera, lo monstruoso, la singularidad de la carne que se expresa en la multitud, se opone frontalmente a las formas visibles y ocultas de "una nueva eugenesia que contribuye a sustentar el poder dominante" (Hardt \& Negri, 2004, p. 232). La carne suma la experiencia misma de los sentidos, de los deseos, de los afectos, el amor y las pasiones, todo eso es monstruoso para la ética cristiana que funda el liberalismo económico y perpetúa, algunas veces de forma tácita, otras de forma evidente, esas formas de eugenesia que pretenden negar la elementalidad de la carne.

Esa elementalidad no solo es encargada de tejer a la multitud, sino también teje la vida en cada uno de sus momentos únicos, irrepetibles y agotables. El bien, como sugería Spinoza ${ }^{11}$, es el resultado de la mezcla benéfica entre los cuerpos: la capacidad transformadora de los cuerpos y las pasiones que entre ellos se realizan al mezclarse es a la larga el origen del bienestar. De ese modo, los monstruos no son monstruos por el orden de su carne, sino porque esa carne está cargada de alegría, vida, amor, dolor y pasión propia de este mundo, dado que ha podido librarse de los límites morales de los hábitos. Pero, evidentemente, para articular esa monstruosidad, para afirmarla como un acto constructor de subjetividad y, con ello, para que sea capaz de subvertir lo común ante el biopoder, es necesario que se manifieste. Allí lo monstruoso se afirma como cuerpo en performance, ya que, como se dijo, no importa qué es un cuerpo, sino lo que puede hacer para entablar un conjunto de crecimientos rizomáticos, descentrados, horizontales y de acoples múltiples, en el sentido otorgado por Deleuze y Guattari (Deleuze \& Guattari, 2000, pp. 9-29).

La performance, como afirman Negri y Hardt, se opone claramente a la noción de hábito, lo desplaza y se plantea como la noción nuclear para las formas de producción biopolíticas y la construcción de lo común en la presente época. Como afirman Hardt y $\mathrm{Ne}$ gri, la paradoja propia del feminismo al respecto del cuerpo, -en tanto lugar de su opresión y, por otra parte, lugar de la especificidad necesaria y monstruosa para la práctica feminista-, se resuelven con una performatividad que reafirma al cuerpo en el común de la carne social, dado que ejerce sobre él una transgresión en contra de hábitos impuestos desde el patriarcado. Cuestión que ejemplifica con claridad el Colectivo FEMEN, quien se refiere así a esa paradoja corporal bajo la cual fundamentan su performance:

otra en movimientos sociales, comunitarios, entre otros.

${ }^{11}$ Siguiendo la lectura de Deleuze en Spinoza, filosofía práctica (Deleuze, 2009)

ESCENA. Revista de las artes, 2021, Vol. 81, Núm. 1 (julio-diciembre), pp.18-43 
En el principio, era el cuerpo, el sentimiento del cuerpo de la mujer, sentimiento de alegría porque era esplendido y libre. Después, era la injusticia, tan filosa que la sentías en tu cuerpo, inmovilizaba tu cuerpo, obstaculizándolo, y luego te encontraste rehén de tu propio cuerpo. Por lo que giraste tu cuerpo contra la injusticia, movilizando cada célula de tu cuerpo para luchar contra el patriarcado y la humillación. Dile al mundo: ¡Nuestro Dios es una mujer! (FEMEN, 2016).

Como se puede apreciar, la paradoja de cuerpo en FEMEN tiene un correlato en la escritura bíblica como parodia al primer versículo de Juan: "en el principio existía el Verbo, y el Verbo estaba con Dios, y el Verbo era Dios". Palabra de Dios, patriarcado y el cuerpo femenino se enfrentan desde esta voz inaugural. No es casual, por supuesto, que en las manifestaciones de FEMEN lo cuerpos desnudos sean cargados con inscripciones lingüísticas, infringidas en colectivo previamente. Por medio de ese texto escrito "a mano" de forma colectiva, se articulan cuerpo con cuerpo, mujer con mujer, bajo el ejercicio cooperativo de una inscripción contra-teológica previa que deberá ejecutarse. De esa forma, cuerpo y lenguaje sobre él cumplen esa función colectivizadora e intersubjetiva que sobrepasa el límite espectacular de las interrupciones eventuales o las proclamas esporádicas contra los hábitos, gracias a ese doble proceso de inscripción bajo la potencia de un acople colectivo y la ejecución como fuga o trayecto singular.

Lo que exponen las acciones incisivas de FEMEN es que cuerpo y lenguaje siempre están atados y, en su articulación, yace un acto performático que produce significaciones sociales y colectividad. Como recuerda Judith Butler (2007), en sintonía con otras autoras feministas, el cuerpo y el sexo, el acople primario de la carne, también es una construcción social convencionalizada como una práctica performada que se realiza constantemente y que, por tanto, debe articularse en contra de los gestos naturalizados y convencionalizados patriarcalmente:

La postura de que el género es performativo intentaba poner de manifiesto que lo que consideramos una esencia interna del género se constituye a través de un conjunto sostenido de actos, postulados por medio de la estilización del cuerpo basada en el género. De esta forma se demuestra que lo que hemos tomado como un rasgo "interno" de nosotros mismos es algo que anticipamos y producimos a través de ciertos actos corporales, en un extremo, un efecto alucinatorio de gestos naturalizados (Butler, 2007, p. 17). 
Multitud y resistencia en el marco del "imperio" contemporáneo,

Artículo según Antonio Negri y Michael Hardt

Imagen 3. Sin título, FEMEN World

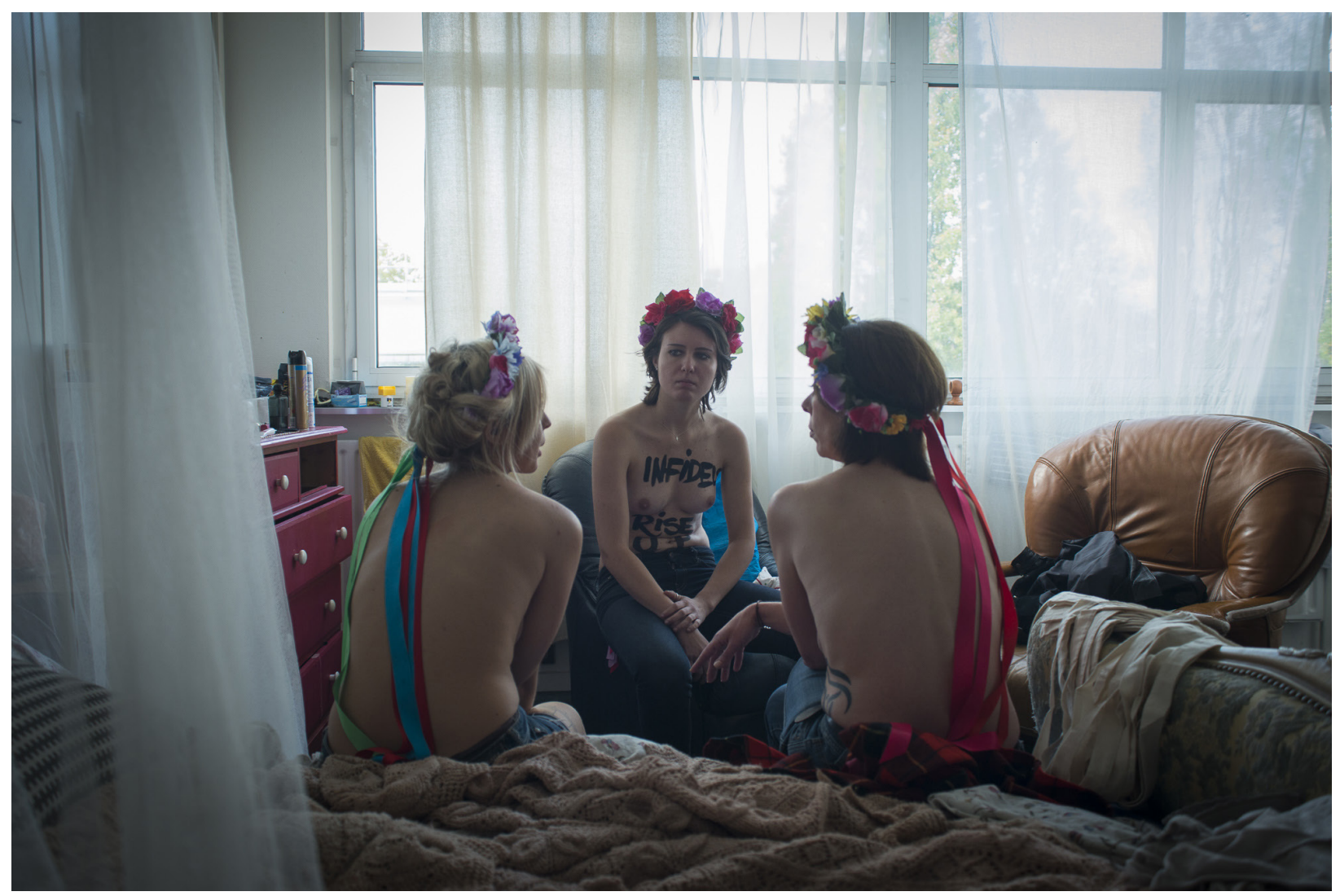

Fuente: Gouriou, V. (2014-2015).

Dado que incluso el sexo, la conexión más elemental de la carne, es algo producido y reproducido constantemente en los cuerpos de forma diaria, para el feminismo y otros movimientos como el Queer, es posible y necesario subvertirlo en sus representaciones sociales, en la simbología performática de un "uso diario". De esa manera, los cuerpos en su articulación asumen su rol como máquinas productoras de signos, que a su vez denuncian la naturalización de los mismos. Hardt y Negri (2004), siguiendo a Butler y su noción queer, afirman que:

La política "queer" es un excelente ejemplo de un proyecto performativo colectivo de rebelión y de creación. No se trata en realidad de una afirmación de las identidades homosexuales, sino de una subversión de la lógica de la identidad en 
general. No hay cuerpos "queer", sino solo carne "queer" que reside en la comunicación y la colaboración de la conducta social (Hardt \& Negri, 2004, p. 236).

\section{Imagen 4. Sin título, FEMEN World}

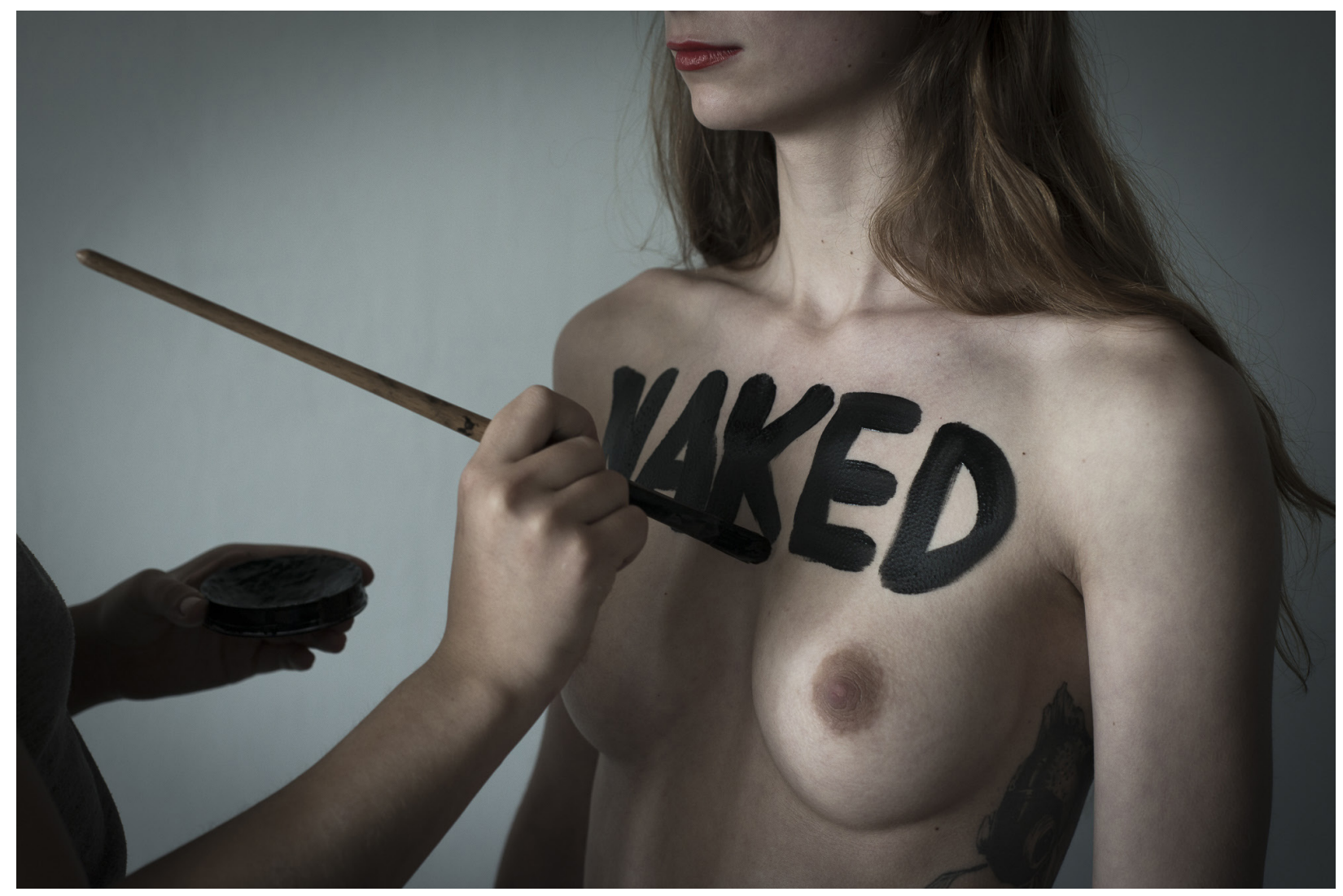

Fuente: Gouriou, V. (2014-2015).

Por tanto, el proyecto performativo del activismo, su gestualidad y manifestación excesiva, carga bajo la reflexión y potencia un conjunto de políticas disruptivas asentadas en la apropiación de la vida diaria, en el común de los cuerpos y en el lenguaje, en tanto es a través de esa articulación por la cual se subvierte la función transitiva por una función de significación. Es por medio de la performatividad que se distinguen las formas de biopoder que se ejercen e imponen socialmente a través del ejercicio económico del imperio, de las formas de resistencia biopolíticas que producen de forma excesiva lo común. Es ahí donde lo performático, en su naturaleza carnavalesca y excesiva, debe irrumpir para el rebalse 
Multitud y resistencia en el marco del "imperio" contemporáneo,

Artículo según Antonio Negri y Michael Hardt

del modelo productivo post-fordista y, con ello, producir nuevas formas de organización política basadas en la singularidad de la carne. Allí yace la potencia misma del arte para la configuración de esa resistencia biopolítica que se afirma a sí misma para, por medio de la creatividad, los excesos y la reflexión crítica, configurar y articular la carne para la producción de lo común.

Como señalan Negri y Hardt, la producción de lo común siempre genera un excedente "que no puede ser expropiado por el capital ni capturado en la regimentación del cuerpo político global" (Hardt \& Negri, 2004, p. 249). Ese excedente, ese conjunto de producción desbordada, es sustancial para que los antagonismos y la indignación se conviertan en acción: "la privación tal vez engendre cólera, indignación y antagonismo, pero la revuelta solo se genera desde la riqueza, es decir como resultado de un excedente de inteligencia, experiencia, conocimientos y deseos" (Hardt \& Negri, 2004, pp. 249-250). Por consiguiente, como concluyen los autores, el exceso es el pilar sobre el cual se sostienen las luchas de resistencia biopolítica y al mismo tiempo el factor elemental para su propagación, dado que articula el recubrimiento de los cuerpos en nodos expansivos en contra de las máquinas bélicas, que no son otra cosa, como afirman Deleuze y Guattari, que destructoras de todo excedente y productoras de precariedad ${ }^{12}$. De esta manera, el exceso es el motor del carnaval y el motor de la resistencia biopolítica ante el consumo nefasto de la guerra imperial.

Lo carnavalesco es dado por la polifonía, la cual trasciende la pluralidad y la sincronía de las voces y que abarca la pasión, la urgencia de las mismas y la instrumentalización que la expresa (las máscaras, la utilería, el vestuario, los escenarios). Tales excesos constituyen una teatralidad, una polifonía que fundamenta al carnaval como momento singular de excepción en la vida normada, pero que se traduce y se ejecuta de forma subversiva en los diversos movimientos de protesta civil en las últimas décadas. Estos movimientos son pasionales, corporales, de indignación y enojo, pero también de júbilo y alegría. Por ejemplo, la brillantina púrpura ha tenido un rol esencial en la última marcha de indignación feminista en Ciudad de México (17 de agosto de 2019); esa brillantina es un claro ejemplo de una articulación entre la reacción colérica y la reivindicación festiva de la resistencia.

\footnotetext{
${ }^{12}$ Así lo proponen los autores: "en efecto, el excedente como contenido específico de la sobrecodificación no solo debe ser almacenado, sino también absorbido, consumido, realizado. Esta exigencia económica de una absorción del excedente es sin duda uno de los principales aspectos de la apropiación de la máquina de guerra por el Estado imperial: desde el principio, la institución militar es uno de los medios más poderosos para absorber el excedente” (Deleuze \& Guattari, 2000, p. 455).
}

ESCENA. Revista de las artes, 2021, Vol. 81, Núm. 1 (julio-diciembre), pp.18-43 
Se articula, en ese sentido, un doble movimiento de la indignación colérica y la acción jubilosa en contra del biopoder desde los carnavalesco. De tal forma, es común observar cómo estas manifestaciones están altamente teatralizadas y llenas de objetos de utilería (como uniformes, disfraces, monigotes, proclamas poéticas, brillantina (glitter), cantos, citas e intertextos) y de objetos utilitarios reconvertidos en accesorios-poéticos de seguridad (como los libros-barrera), distractivos (como espejos reflectores, piedras-inflables o cobblestones) o en instrumentos escandalosos (como las cacerolas). Todos estos elementos crean exceso y representan una gran pluralidad de voces que se conectan en una diversidad de anclajes para escapar a su vez de su función como bienes de consumo (en el caso de los objetos) y de su marco histórico o artístico previo (en el caso de las citas, los vestuarios y los personajes teatralizados como Guy Flawkes), para sumarse a una nueva significancia en la multitud monstruosa.

En la muestra Disobedient Object, organizada por el Victoria and Albert Museum de Londres en el año 2015 (Flood \& Grindon, 2014), se exhibió una multiplicidad de estos objetos utilitarios resemantizados funcionalmente en las diferentes manifestaciones, marchas y reivindicaciones políticas. Como afirmaban los curadores de dicha muestra en la introducción de su catálogo, todos estos objetos forman parte de las múltiples cabezas de la Hydra, tanto las cortadas como las que renacen por partida doble, dado que ambas posibilitan la construcción de una historia desde abajo, polifónica, que debe hacer justicia a ese plural de protagonistas silenciados bajo el heroísmo de la espada de Hércules.

Por último, la polifonía también se aprecia en su propio sistema de organización horizontal y en su metáfora, cuestión implementada en las manifestaciones y acampadas de la multitud como las realizadas el 15 de mayo en el 2011 en España, donde se potencia el intercambio de una infinidad de relatos de sujetos singulares en direcciones diversas en un mismo escenario: el espacio público. En esas formas de organización política, opera también una acción performática simbólica sobre la desjerarquización del poder y la reconversión del espacio público como un espacio político para la democracia participativa que, a su vez, cuestiona la política gubernamental representativa que se ejerce en congresos y palacios de gobierno. 
Multitud y resistencia en el marco del "imperio" contemporáneo,

Artículo según Antonio Negri y Michael Hardt

\section{Imagen 4. Inflable Cobblestone}

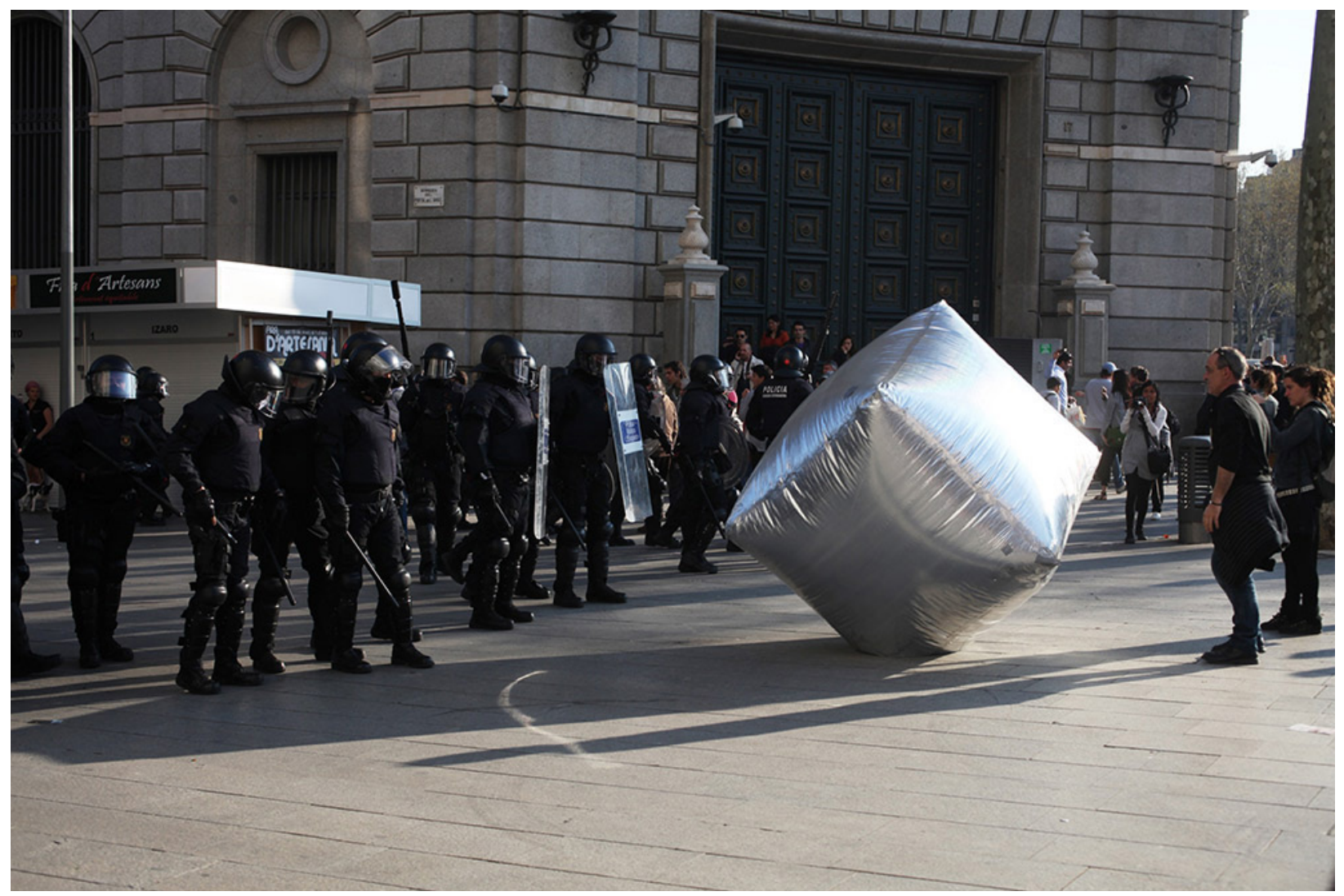

Fuente: Eclectic Electri Collective \& En medio collective. (2012).

Además, esas formas de organización horizontal, situadas en escena en el teatro de la calle, reafirman una cultura popular que alimenta lo política y que, comúnmente, se le ha ocultado bajo la sombra del arte hegemónico occidental y su connivencia con los regímenes de verdad racionales. Pero, como demuestra Bajtín en su famoso libro La cultura popular en la Edad Media y en el Renacimiento: el contexto de François Rabelais (Batjín, 1999), las formas de creatividad que se desarrollaban por entero en la vida pública y en los espacios comunes también afectaban los regímenes de poder como formas de resistencia desde las épocas consideradas más "ilustres" por la Historia del arte. Es, a partir de Batjin, que Negri y Hardt subrayan la importancia de trasponer la naturaleza polifónica del relato popular al ejercicio de lo biopolíico: "ya no existe un centro que dicte el sentido, sino que este surge únicamente del intercambio entre todas las singularidades en diálogo" [el destacado es del 
original] (Hardt \& Negri, 2004, p. 248). De ese modo, la asamblea teatralizada se configura como un símbolo necesario para conducir el carácter polifónico del carnaval en las formas de organización política propias de la multitud. El arte, en ese sentido, no es repercusión ni consecuencia de la política como ha sugerido siempre el relato moderno, sino aquello que participa de su fundación.

\section{Conclusiones}

Las teorías sobre las condiciones imperiales del presente y el ejercicio de su biopoder bajo una guerra continua que postulan Negri y Hardt permiten vislumbrar nuevas formas de resistencia desde la redimensión carnavalesca y polifónica de la multitud, como un conjunto de singularidades que se tejen en su propia performatividad. La condición simbólica y la potencia del arte para suscribir estas nuevas formas de biopolítica no es una cosa menor, ya que esta no solo se presenta extraña para toda una política tradicional y hegemónica, sino que, además, se despliega como sumamente peligrosa para ellas, en tanto evidencia, como su contraparte, las marcas de sus imposiciones ideológicas, las cuales se convencionalizan y naturalizan bajo el ejercicio del biopoder. Por ello, la política tradicional o conservadora no duda en señalar ese mismo carácter simbólico como inoperante, propio de un compromiso light o como postureo de las nuevas izquierdas, sinónimo de falsedad y mentira, mientras hacen pasar sus símbolos convencionalizados como una verdad entregada por la historia, la cultura o la tradición, en otras palabras, en la perpetuación ideológica del capitalismo patriarcal.

Sin embargo, en este imperio difuso y extenso que diagnostican Negri y Hardt (donde los sujetos políticos de la izquierda moderna parecen haber sucumbido en su pretensión de devenir mayoría), es precisamente el feminismo el que hoy encarna -bajo la metáfora de la Hydra- una plenitud de nodos potenciales para vinculan constantemente arte y política afianzado en los cuerpos y lo personal. Bajo la elementalidad corporal y de sus mezclas, el feminismo ha convertido su objeto, que no es la mujer sino el cuerpo, en ese territorio en disputa donde se suscriben nuevos esquemas de apropiación: inscripción de una micropolítica que proyecta sus líneas de fuga y retorno para hacer posible el acople y la articulación de una infinidad diversa de luchas, siempre minoritarias.

Así, en este imperio que se oculta, construido sobre la decadencia de la democracia actual, un retumbo e insistencia carnavalesca poco a poco va construyendo y consolidando una nueva relación entre arte y política que aquí se ha definido como de resistencia biopolítica, dirigidas no a la pretensión mayoritaria de los colectivos políticos molares, sino 
Multitud y resistencia en el marco del "imperio" contemporáneo,

Artículo según Antonio Negri y Michael Hardt

al contrario, de un devenir minoría: singularidad y, a su vez, multitud. Es esa precisamente su importancia y transcendencia para el arte y su enseñanza, ya que este, como singularidad siempre en minoría, arrastra la potencia de construir colectividades, manteniendo y preservando las diferencias, reconociendo la pluralidad como un valor esencial para responder aquella vieja pregunta que se hacía Roland Barthes (2003) en sus últimos seminarios: ¿cómo vivir juntos?

En ese sentido, lo que se ha pretendido con este texto es replantear algunas ideas sobre el vínculo entre arte y política, que permitan no solo entender los fenómenos que han permeado los límites entre ambas prácticas, sino que, además, faculten señalar nuevas formas de articulación en la construcción de nuevas subjetividades y colectividades, necesarias y pertinentes para la investigación en arte en el marco de la universidad pública.

\section{Referencias}

Barthes, R. (2003). Cómo vivir juntos. Buenos Aires: Siglo XXI Editores Argentina.

Batjín, M. (1999). La cultura popular en la Edad Media y en el Renacimiento: el contexto de François Rabelais. Madrid: Alianza.

Bradley, W., \& Esche, C. (2007). Art and social change. London: Tate publishing.

Butler, J. (2007). El género en disputa. Barcelona: Espasa Libros.

Deleuze, G., \& Guattari, F. (2000). Mil mesetas. Valencia: Pretextos.

Eclectic Electri Collective \& En medio collective. (2012). Inflable Cobblestone. [Fotografía]. Recuperado de: https://www.vam.ac.uk/blog/disobedient-objects/tools-for-action-interview-with-artur-van-balen

FEMEN. (01 de 06 de 2016). FEMEN oficial blog. Obtenido de About us: http://femen.org/ about-us/

Flood, C., \& Grindon, G. (2014). Disobedient Objects. Londres: V\&A Publishing.

Foucault, M. (1995). Nietzsche, Freud, Marx. Buenos Aires: El cielo por asalto.

Foucault, M. (2009). Nacimiento de la biopolítica. Madrid: Akal.

Gouriou, V. (2014-2015). Sin título, FEMEN World. [Fotografía]. Recuperado de https://vincentgouriou.com/femen-pour-les-libertes

ESCENA. Revista de las artes, 2021, Vol. 81, Núm. 1 (julio-diciembre), pp.18-43 
Gouriou, V. (2014-2015). Sin título, FEMEN World. [Fotografía]. Recuperado de https://vincentgouriou.com/femen-pour-les-libertes

Hardt, M., \& Negri, A. (2004). Multitud. Guerra y democracia en la era del Imperio. Barcelona: Ramdom House Mondadori.

Huybrecht, E. (2014). Guerrilla Girls en el V\&A Museum, Londres. [Fotografía]. Recuperado de https://llickr.com/photos/15979685@N08/15330478694

Kleim, N. (2007). La doctrina del Shock. Barcelona: Paidós

Kruger, B. (1989). Untitled (your body is a battleground). [Arte]. Recuperado de https://www. thebroad.org/art/barbara-kruger/untitled-your-body-battleground

Rosler, M. (1969-1972, 2004-2008). House beautiful: Bringing the War Home. [Serie de fotomontajes].

Taylor, A. (Dirección). (2008). Examined Life [Película]. 